\title{
Optimum Synthesis of Mesoporous Silica Materials from Acidic Condition
}

\author{
Hong-Ping $\operatorname{Lin}^{\mathrm{a}}$ ( 林弘萍), Chin-Lung Kuo ${ }^{\mathrm{b}}$ ( 郭錦龍 ), \\ Ben-Zu Wan ${ }^{\mathrm{b}}$ ( 萬本儒) and Chung-Yuan $\mathrm{Mou}^{\mathrm{c} *}$ (牟中原) \\ ${ }^{a}$ Department of Chemistry, National Cheng Kung University, Tainan 701, Taiwan, R.O.C. \\ ${ }^{\mathrm{b}}$ Department of Chemical Engineering, National Taiwan University, Taipei 106, Taiwan, R.O.C. \\ ${ }^{\mathrm{c}}$ Department of Chemistry and Center for Condensed Matters Sciences, National Taiwan University, \\ Taipei 106, Taiwan, R.O.C.
}

\begin{abstract}
On the basis of the mixtures composed of $\mathrm{C}_{n}$ TMAB/acids/TEOS/water, the mesoporous materials with well-ordered hexagonal structures can be synthesized under acidic condition $(\mathrm{pH}<1.0)$ with a careful control of the silica condensation. However, the induction period time for the formation of surfactant-silica precipitation varied with the employed acid source and decreased in the series: $\mathrm{HNO}_{3}<\mathrm{HBr}<\mathrm{HCl}<\mathrm{H}_{2} \mathrm{SO}_{4}$ at the same acid concentration. Increasing the acid concentration not only induced a fast precipitation rate, but also provoked more nuclei seeds formation and reduced the particle size of the mesoporous silica products. A proper aging time is also significant for getting the well-ordered mesoporous materials via acid route, and a longer aging time would induce a gradual decomposition of the mesostructures. For morphology, in acid synthetic medium, various interesting shell-like curved patterns on the surface of mesoporous silica particles were formed. The physical properties (such as d-spacing, pore size, BET surface area and porosity) of the calcined mesoporous silica are almost not affected by the nature of the acid source, but the pore size of the mesoporous materials can be tailored by varying the chain length of the surfactant. Adding the proper amount of ammonia solution for adjusting the $\mathrm{pH}$ value between 8-10 can improve the hexagonal mesostructures order of the mesoporous materials while maintaining the original morphology.
\end{abstract}

\section{INTRODUCTION}

The mesoporous material based on silica has been intensively investigated for scientific interests and practical applications. ${ }^{1,2}$ In particular, the discovery of a new family of mesoporous materials M41S by researchers of Mobil Oil Corp. has attracted great attention by scientists and engineers. ${ }^{3,4}$ These M41S family's mesoporous materials with uniformly sized nanochannels, tunable pore size (1.0-10.0 $\mathrm{nm})$ and high surface area $\left(\sim 1000 \mathrm{~m}^{2} / \mathrm{g}\right)$ have been a focus of recent applications for catalysts, catalytic supports, molecular separation, chemical sensors, electronic and optical devices, and advanced materials. ${ }^{5-11}$ Typically, the mesoporous materials are synthesized in alkaline condition, where the cationic quaternary ammonium surfactants $\left(\mathrm{S}^{+}\right)$combine with the negative-charged silicate species $\left(\mathrm{I}^{-}\right)$through strong electrostatic interactions $\left(\mathrm{S}^{+} \mathrm{I}^{-}\right) .{ }^{12,13}$ Due to the strong electrostatic interactions, the surfactants and silicate oligomers prefer to combine together to form the mesostructural particles, rather than aggregate together to form a hierarchical structure or grow on the surface of other substrates. This behavior hampers the alkaline-made mesoporous materials in morphologies tailoring such as in low dielectric constant material. For the applications of the alkaline-made mesoporous silica in semiconductors, removing the high-concentration sodium ions, existing in sodium silicate as silica source, is still a serious problem. However, Huo et al. in 1994, ${ }^{14}$ has offered another synthesis method for manufacturing mesoporous material in an acidic condition $(\mathrm{pH}<1)$, where the silica source is tetraethyl orthosilicate, and the acidic source is hydrochloride acid. In synthetic composition there are no alkaline metal ions. Under such a strong acid condition, the silica species are cationic $\left(\mathrm{I}^{+}\right)$and combine with the cationic surfactants $\left(\mathrm{S}^{+}\right)$via a bridged counterion $\left(\mathrm{X}^{-}\right)$. Owing to this weaker hydrogen-bonding interaction $\left(\mathrm{S}^{+} \mathrm{X}^{-} \mathrm{I}^{+}\right.$or $\left.\mathrm{S}^{+} \mathrm{X}^{-} \mathrm{I}^{0}\right)$ in the mesoporous materials prepared from the acid route, the surfactant/counterion/silica mesostructures can gradually grow into macro-scaled (i.e. micro- or millim-metered) morphologies and homogeneously coat on the surface of various substrates (such as silicon wafer and mica) or interface between silica water/air and water/oil. Thus, various desired hierarchical structures (i.e. gyroidal spheres, silica fiber and

Dedicated to the celebration of the seventieth anniversary of Chemical Society the located in Taipei.

* Corresponding author. Tel : +886-2-33665251; fax: +886-2-23660954; e-mail: cymou@ccms.ntu.edu.tw 
ropes) and the thin mesoporous silica film has been successfully synthesized by using TEOS as silica precursor and cationic surfactant (quaternary ammonium halides) as the structure-directing agent at room temperature. ${ }^{15-24}$ To the best of our knowledge, the acidic route is thus the most popular way to get interesting and versatile morphologies. At the same time, a mild extraction in polar solvent can easily remove the template $\mathrm{S}^{+} \mathrm{X}^{-}$, and leave a pure silica framework without a trace of alkaline metal ionic species.

The synthesis procedures and compositions for preparing the acid-made mesoporous materials have been presented in previous studies, ${ }^{14}$ and some kinetic experiments of the micellar surface catalysis process and some controlling factors have also been explored in one of our previous papers. ${ }^{15}$ However, the considerable controlling factors that sensitively affect the silica condensation rate and degree have not been discussed in detail yet. Thus, in this paper, we continue to thoroughly investigate a number of various chemical and physical factors (including concentration of acid, acid source, ageing time and $\mathrm{NH}_{4} \mathrm{OH}$ addition), which have great influences on the particle size, surface patterns, morphology and orderness of the acid-made mesostructures. A careful control on the silica condensation rate, condensation degree and surfactant-silica interaction strength could provide one essential idea to design the particle size, product quality control and orderness of the acid-made mesoporous silicas for fitting the desired applications.

\section{EXPERIMENTAL}

\section{Materials}

The organic template, alkyltrimethylammonium bromide, denoted as $\mathrm{C}_{\mathrm{n}} \mathrm{TMAB}(\mathrm{n}=14-18)$, was obtained from Acrôs. The silica source was tetraethyl orthosilicate (TEOS, Acrôs, 98\%) from Acrôs. Sulfuric acid $\left(\mathrm{H}_{2} \mathrm{SO}_{4}\right)$, hydrochloric acid $(\mathrm{HCl})$, hydrobromic acid $(\mathrm{HBr})$, nitric acid $\left(\mathrm{HNO}_{3}\right)$ and ammonia $\left(\mathrm{NH}_{4} \mathrm{OH}, 30 \%\right)$ were purchased from Merck, Acrôs or Janssen Chimica. All chemicals were used without further purification.

\section{Synthesis}

A given amount of the surfactant $C_{n}$ TMAB was dissolved into water with stirring to form a clear solution and then the proper amount of acid source was added. After stirring 10 minutes at synthetic temperature of $30-40{ }^{\circ} \mathrm{C}$, TEOS was added into that aqueous solution with stirring at 300-500 rpm. The gel composition is (in moles): 1 surfactant: (3.0 15.0) TEOS: (10.0 - 80.0) HX: $\left(500\right.$ - 3000) $\mathrm{H}_{2} \mathrm{O}$. The de- tailed synthesis procedure and chemical components can be found elsewhere. ${ }^{25}$ The induction time was measured by observing a white precipitation formation. For exploring the relationship of aging time and meso-structural orderness of the silica product, the gel mixture was aged for different agitation times. For improving the orderness of the mesoporous silica, a suitable amount of $1.0 \mathrm{M} \mathrm{NH}_{4} \mathrm{OH}$ aqueous solution was added to adjust the $\mathrm{pH}$ value to 8-9. The resulting solid product was recovered by filtration, washed with deionized water, dried at $100{ }^{\circ} \mathrm{C}$ or room temperature. To remove the organic species occluded in the nanochannels of the mesoporous materials, the as-synthesized sample was calcined in air at $560{ }^{\circ} \mathrm{C}$ for $6 \mathrm{hr}$.

\section{Characterization}

Powder X-ray diffraction (XRD) patterns were collected on a Scintag X1 diffractometer using $\mathrm{Cu} \mathrm{K}_{\alpha}$ radiation $(\lambda=0.154 \mathrm{~nm})$. The $\mathrm{N}_{2}$ adsorption-desorption isotherms were obtained at $77 \mathrm{~K}$ on a Micrometric ASAP 2010 apparatus. The samples were degassed at $250{ }^{\circ} \mathrm{C}$ under $10^{-3}$ torr for 6 $\mathrm{hr}$ before analysis. The scanning electron microscopy (SEM) was taken on an Hitachi S-800 operated at an accelerating voltage of $20 \mathrm{keV}$. Elementary analysis data were taken from the Perkin-Elmer 2400.

\section{RESULTS AND DISCUSSION}

\section{Surfactant-Silica Mesostructures Formation Rate are Dependent on Acid Concentration and Source}

Previously, when we investigated the kinetics of formation of the mesoporous materials, which are dependent on $\left[\mathrm{H}^{+}\right],\left[\mathrm{X}^{-}\right]$and the binding ability of $\mathrm{X}^{-}$, we always had to control the ionic strength by adding a huge amount of sodium salts to those reaction composites. ${ }^{25}$ However in real synthesis composites, the sodium salts are not necessary for synthesizing the acid-made mesoporous materials and are very undesirable for low-dielectric films preparation. It is, thus, necessary to establish a relation between the mesoporous silica materials formation and acid concentration and acid sources as a criterion for preparing the acid-made mesoporous silicas.

Fig. 1 shows that the induction time of the surfactants-silica precipitation decreases with the concentration of acids. This result indicates that the $\mathrm{H}^{+}$can catalyze the polymerization of the silica species at $\mathrm{pH}<1$, and is parallel to previous reports. ${ }^{28}$ Besides the $\left[\mathrm{H}^{+}\right]$effect, the induction time is also dependent on the acid sources. ${ }^{25}$ At the same $\left[\mathrm{H}^{+}\right]$, the induction time decreases follows the sequence: $\mathrm{HNO}_{3}<\mathrm{HBr}$ $<\mathrm{HCl}<\mathrm{H}_{2} \mathrm{SO}_{4}$. To explain this, let's examine the formation 
process of the mesoporous samples from the acid route:

$$
\begin{aligned}
& \equiv \mathrm{Si}-\mathrm{OEt}+\mathrm{H}_{2} \mathrm{O}+\mathrm{H}^{+} \rightarrow \equiv \mathrm{Si}-\mathrm{OH}_{2}{ }^{+}+\mathrm{EtOH} \\
& \sim \mathrm{X}^{-}+\equiv \mathrm{Si}-\mathrm{OH}_{2}{ }^{+} \rightarrow \sim \mathrm{X}^{-+} \mathrm{H}_{2} \mathrm{O}-\mathrm{Si} \equiv \\
& \sim \mathrm{X}^{-}{ }^{+} \mathrm{H}_{2} \mathrm{O}-\mathrm{Si} \equiv \rightarrow \sim \mathrm{X}^{-} \mathrm{HO}-\mathrm{Si} \equiv
\end{aligned}
$$

Where $\sim \oplus=\mathrm{C}_{\mathrm{n}} \mathrm{TMAB} ; \mathrm{X}^{-}=\mathrm{NO}_{3}{ }^{-}, \mathrm{Cl}^{-}, \mathrm{Br}^{-}$or $\mathrm{S}_{1 / 2} \mathrm{O}_{2}^{-}$

Step (1) is the hydrolysis process of the silane TEOS. This step is rapidly accomplished in high-acidity condition $(\mathrm{pH}<1)$ at the presence of the $\mathrm{C}_{\mathrm{n}}$ TMAX surfactant. Then the silanol group of the hydrated TESO is protonated in the acid condition. The cationic silica species then combines with the $\mathrm{S}^{+} \mathrm{X}^{-}$micelles through an electrostatic interaction at the intermediate state. (Step (2)) Then, the $\mathrm{S}^{+} \mathrm{X}^{-}$sites catalyze condensation reaction of the positive-charged silica species $\left(\mathrm{I}^{+}\right)$in the acidic route. Thus, the counterion from acid source with the larger binding affinity can generate more $\mathrm{S}^{+} \mathrm{X}^{-}$active sites, which accelerate the silica condensation. This behavior should follow the order in the binding affinity (or hydrophobicity) of the counterion in the well-known Hofmeister series: $\mathrm{NO}_{3}{ }^{-}>\mathrm{Br}^{-}>\mathrm{Cl}^{-}>\mathrm{SO}_{4}{ }^{2-2} \cdot{ }^{29,30}$ The counterion with less binding strength has less efficiency to catalyze the silica species poly-

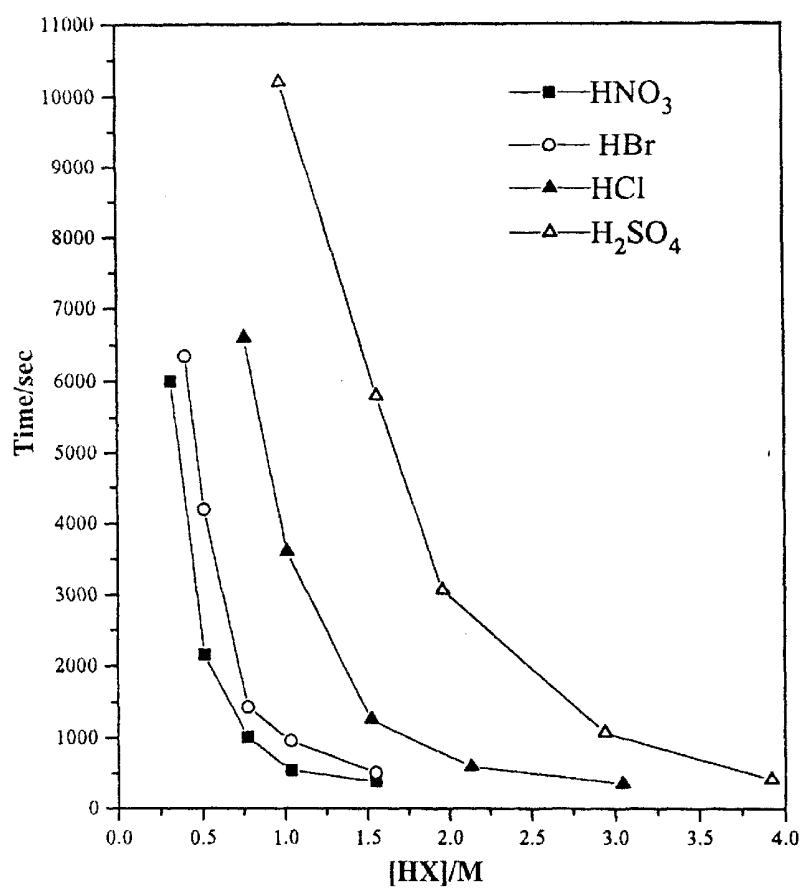

Fig. 1. A plot of the induction time of the silica-surfactant precipitation formation from $1.0 \mathrm{C}_{16}$ TMAB: (3.0-55.0) HX : 4.76 TEOS : $762 \mathrm{H}_{2} \mathrm{O}$ compositions; $\mathrm{HX}=\mathrm{HNO}_{3} ; \mathrm{HBr} ; \mathrm{HCl} ; \mathrm{H}_{2} \mathrm{SO}_{4}$. merization. In the final step (3), the silica species further condenses on the micelle surface and forms the mesoporous product $\left(\mathrm{S}^{+} \mathrm{X}^{-} \mathrm{I}^{0}\right)$, where the interactions between the surfactant and silica framework are the hydrogen bonding.

\section{Mesostructural Order and Morphology Control}

As shown in the last section, the rate of formation of the mesoporous silica can be controlled by varying counterion species and their concentrations. It would be interesting then to investigate the consequence of varying the rate. The most obvious thing to look for will be the morphology of the product because it is determined by rates of nucleation, growth and aggregation. In this section, we would like to examine the effects on particle size and shape, and surface pattern. In addition, the optimum aging time for getting well ordered meso-structural silicas are also dependent on the acid concentration.

\section{Particle-size control}

Based on the concept of classical crystal growth theory, it is expected that increasing the number of the nuclei seeds will then reduce the crystal size of the product. This should also apply as well to the acid-made mesoporous composites. Fig. 2 shows the scanning electronic microscopy (SEM) figures of the sphere-like particles obtained from the $\mathrm{C}_{16}$ TMABTEOS-HCl- $\mathrm{H}_{2} \mathrm{O}$ components at different acidities. It is obvious that the particle size decreases with an increase of the $\mathrm{HCl} /$ surfactant ratio (denoted as $\mathrm{r}$ ). The size can be tuned in the range from $15 \mu \mathrm{m}$ to $3 \mu \mathrm{m}$ at the $\mathrm{r}$ in the range of 12-77.

The acidity-dependence of the particle size can be explained based on the silica species formation rate. In acid media, the silica species oligomerization is catalyzed by the $\mathrm{H}^{+}$. When the silica oligomers grow to a large enough size, they are energetically favored to combine with the surfactants and form the sub micro-sized nuclei seeds for the formation of mesoporous products during the induction period. ${ }^{30}$ With the increase of the acid concentration, the silica species aggregation rate increases and produces more nuclei seeds in the solution. More seeds make the average particle size smaller. In contrast, less nuclei number and larger particles form at lower acidity. So, this is a convenient way to control the particle size of the mesoporous silicas by adjusting the acidity. This result is one example of nuclei number controlling that is in parallel to a quenching procedure used by Mann's group for producing extremely fine particulates of mesoporous silica in the range of tens of nanometers. ${ }^{31}$

\section{Surface patterns formation}

When making a close examination, one can easily find that the larger particles have a smooth outer shell without any surface patterns (Fig. 2A, B). On the other hand, the smaller 
particles synthesized at higher acidity (Fig. 2C, D) are in gyroidal spheres possessing lots of curved stripes or patterns on their surfaces as previously observed by Ozin's group. ${ }^{32}$ In addition to an $\mathrm{HCl}$ acid source, the mesoporous silicas with obvious surface patterns also can be synthesized by using $\mathrm{HNO}_{3}$. Fig. 3 displays many representative surface patterns on the mesoporous silica particles. Accordingly, the growth of the high-curvature surface patterns may be a kinetic controlling process. This theoretically interesting phenomenon needs further kinetic studies and the corresponding theoretical studies to obtain the correct explanation. Understanding the formation mechanism could provide better understanding of the shape variations on the natural shells and diatoms.

\section{Aging time effect}

Fig. 4A shows the XRD patterns of uncalcined mesoporous products synthesized from the same reaction compositions of $\mathrm{C}_{16} \mathrm{TAMB}-\mathrm{HCl}$-TEOS- $\mathrm{H}_{2} \mathrm{O}$ at $\mathrm{T}=30{ }^{\circ} \mathrm{C}$ for different aging times. We clearly found that the XRD peak widths of the mesoporous sample gradually became broader, and the peak number decreased as well with aging time. In this composition, the aging time of $1 \mathrm{~h}$ is just long enough to get well-ordered mesoporous silicas. Aging for too long will in-
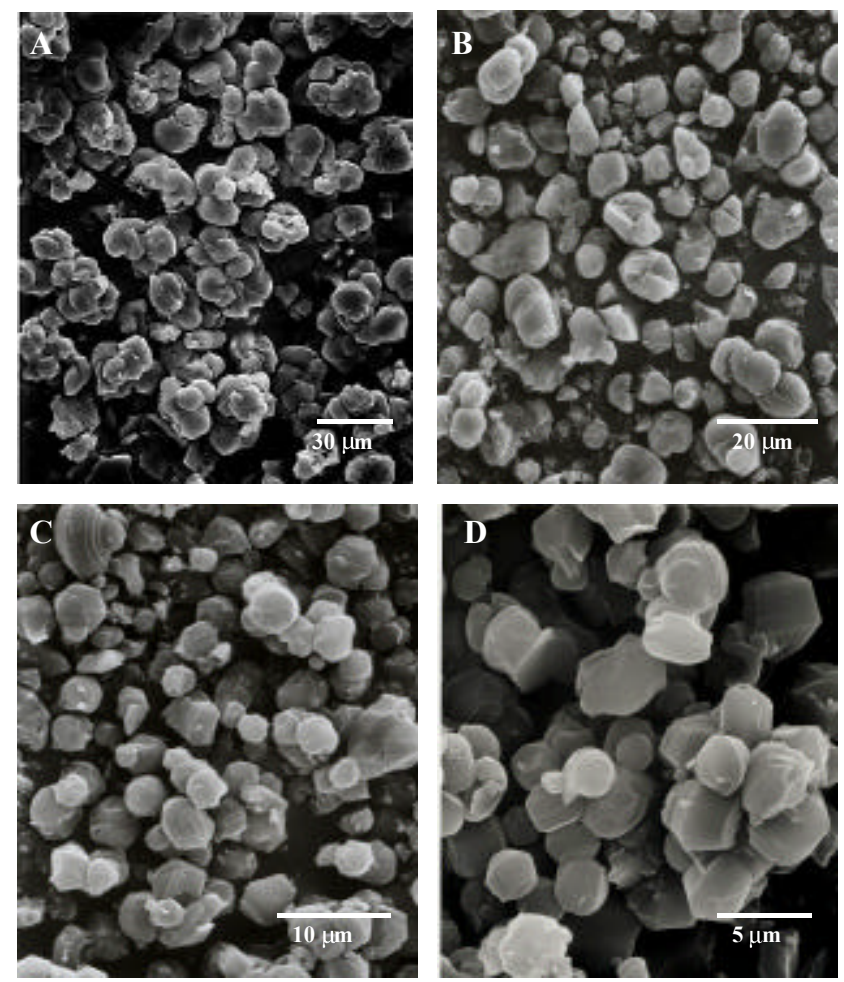

Fig. 2. SEM micrographs of the mesoporous materials obtained from $1.0 \mathrm{C}_{16} \mathrm{TMAB}$ : $\mathrm{HCl}$ : 8.30 TEOS: $1083 \mathrm{H}_{2} \mathrm{O}$ compositions at $30{ }^{\circ} \mathrm{C}$. A. $\mathrm{r}=12.0$; B. $r=34.2$; C. $r=52.3$; D. $r=77.0$. duce a gradual collapse of the hexagonal mesostructures under highly acidic solution. Based on these results, we propose that a mesostructure collapse reaction takes place in the acid-made mesostructures as follows:

$$
\underset{\text { Weak hydrogen bond }}{\sim \oplus \mathrm{X}^{-} \cdots \mathrm{OH}-\mathrm{Si} \equiv \rightarrow \sim \mathrm{X}^{-}+\text {Amorphous }^{\sim} \mathrm{SiO}_{2}(4)}
$$

Owing to the weak hydrogen bonding interactions $\left(\mathrm{S}^{+} \mathrm{X}^{-} \mathrm{I}^{0}\right)$ between the silica wall and the surfactants, the acidmade mesoporous silica products show a stronger tendency
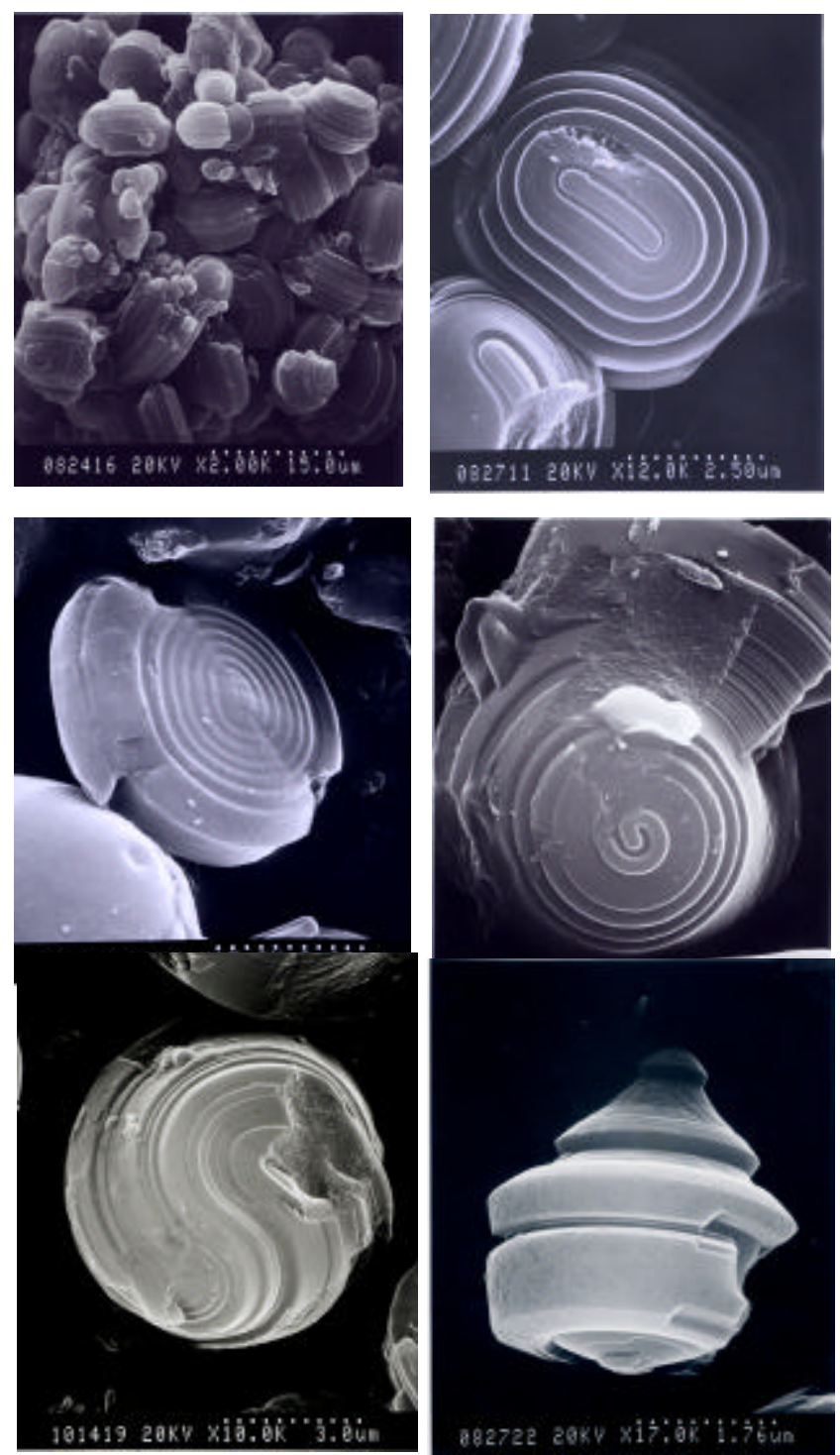

Fig. 3. SEM micrographs of various surface curved patterns on the mesoporous silica particles synthesized from $1.0 \mathrm{C}_{16} \mathrm{TMAB}: 20.5 \mathrm{HNO}_{3}: 8.30$ TEOS: $1083 \mathrm{H}_{2} \mathrm{O}$ compositions at $32{ }^{\circ} \mathrm{C}$ for 12 h. 
towards the more thermodynamically favored separation of surfactant and silica upon further silica condensation. This energetically favorable process therefore step by step induces the formation of amorphous silica. ${ }^{33}$

Comparing the SEM micrographs of the two samples aged for $1 \mathrm{~h}$ and $24 \mathrm{hr}$ (Fig. $4 \mathrm{~B}, \mathrm{C}$ ), it is observed that the particle of the $1 \mathrm{hr}$-aging sample apparently remained as in the individual gyroidal spheres. In contrast, the $24 \mathrm{hr}$-aged sample appeared as a shapeless surfactant-silica aggregation with a lot of tiny particles that can be assigned as amorphous silicas.

Thus a suitable aging time is also an important controlling factor for synthesizing the well-ordered mesostructural silicas under acid condition. Moreover, the optimum aging time to obtained the stable and well-ordered meso-structural silicas are also dependent on the acid concentration and acid source. In general, the acid source with the stronger binding counterion and the higher acid concentration needs less aging
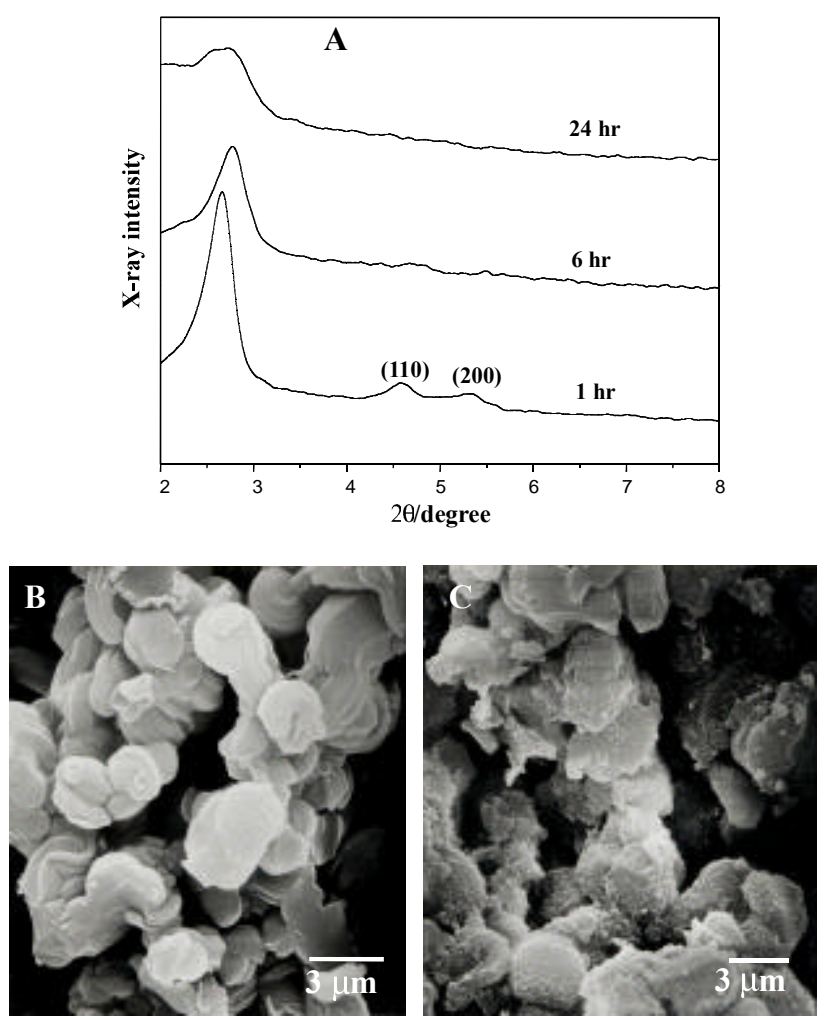

Fig. 4. XRD patterns and SEM and micrographs of the mesoporous materials prepared from $1.0 \mathrm{C}_{16}$ TMAB: $77.0 \mathrm{HCl}: 8.30$ TEOS: $1083 \mathrm{H}_{2} \mathrm{O}$ compositions for different aging time at $30^{\circ} \mathrm{C}$. A. XRD; B. SEM of 2-h aged sample; C. SEM of 16-h aged sample. time to get the well-ordered hexagonal structures. To the best of our knowledge, the investigations of aging time on the mesoporous products have not been previously reported. Without carefully observing the aging time effect, one can not have a good control on the reproducibility and quality of the acid-synthesized mesoporous silicas. Often one may make the wrong explanation and predictions on the experimental results.

\section{Effects of Acid Source on the Physical Properties of the Acid-Made Esoporous Silicas}

As in the aforementioned sections, the silica species aggregation and condensation reactions are relative to the acid concentration and the sources. For making rational compari-
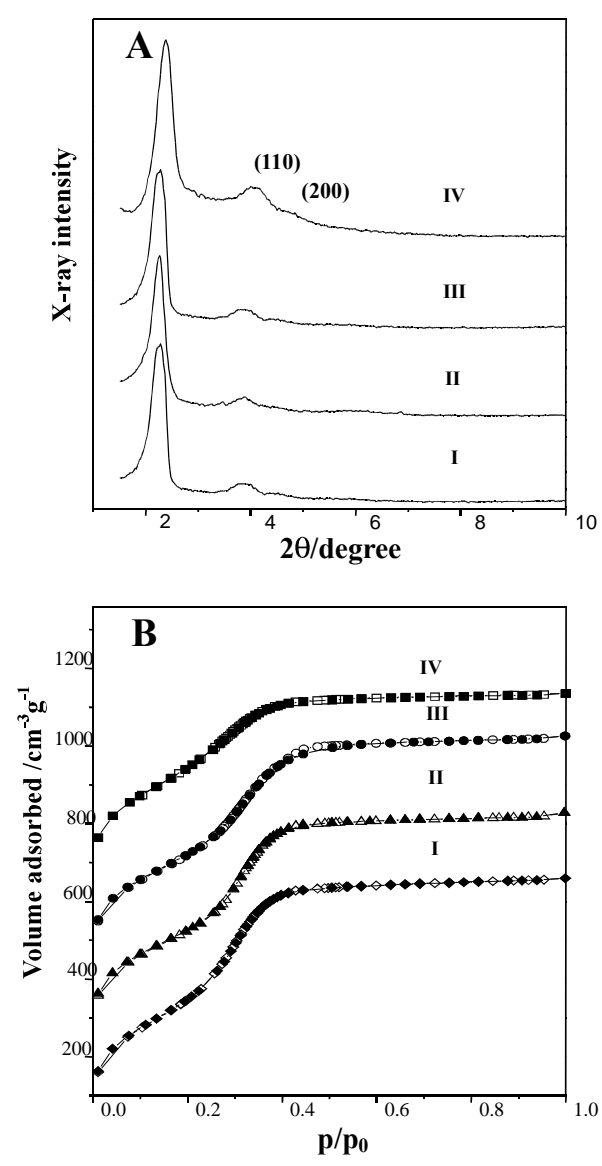

Fig. 5. XRD patterns (A) and $\mathrm{N}_{2}$ adsoption-desorption isotherms (B) of the calcined materials obtained from 1.0 $\mathrm{C}_{16}$ TMAB: $20.5 \mathrm{HX}$ : 4.76 TEOS: 762 $\mathrm{H}_{2} \mathrm{O}$ systems by using different acid sources at $30{ }^{\circ} \mathrm{C}$. I. $\mathrm{HNO}_{3}$ (aging time $=12 \mathrm{~h}$ ); II. $\mathrm{HBr}$ (aging time $=1$ day); III. $\mathrm{HCl}$ (aging time $=2$ day); IV. $\mathrm{H}_{2} \mathrm{SO}_{4}$ (aging time $=2$ day). 
Table 1. Physical Properties of the Acid-Made and Calcined Mesoporous Silica Materials Synthesized from $\mathrm{C}_{\mathrm{n}}$ TMAX-TEOS-HX- $\mathrm{H}_{2} \mathrm{O}$ Components

\begin{tabular}{lccccc}
\hline Surfactant $^{\mathrm{a}}$ & Acid source & $\mathrm{d}_{100}$ (as-made) $/ \mathrm{nm}$ & $\mathrm{d}_{100}$ (calcined)/nm & Pore size $/ \mathrm{nm}$ & BET surface area/m $/ \mathrm{g}$ \\
\hline $\mathrm{C}_{16}$ TMAB & $\mathrm{HCl}$ & 3.98 & 3.60 & 2.33 & 1182 \\
$\mathrm{C}_{16}$ TMAB & $\mathrm{HBr}$ & 3.95 & 3.56 & 2.30 & 1163 \\
$\mathrm{C}_{16}$ TMAB & $\mathrm{H}_{2} \mathrm{SO}_{4}$ & 4.02 & 3.58 & 2.32 & 1143 \\
$\mathrm{C}_{16}$ TMAB & $\mathrm{HNO}_{3}$ & 4.03 & 3.65 & 2.40 & 1032 \\
$\mathrm{C}_{14}$ TMAB & $\mathrm{HNO}_{3}$ & 3.52 & 3.20 & 2.01 & 1083 \\
$\mathrm{C}_{18}$ TMACl & $\mathrm{HCl}$ & 4.36 & 3.83 & 2.66 & 1058 \\
\hline
\end{tabular}

${ }^{\mathrm{a}} \mathrm{C}_{18} \mathrm{TMACl}$ systems were synthesized at $40{ }^{\circ} \mathrm{C}, \mathrm{C}_{16} \mathrm{TMAB}$ and $\mathrm{C}_{14} \mathrm{TMAB}$ at $30^{\circ} \mathrm{C}$.

${ }^{b}$ The values were gotten from the adsorption portion of the $\mathrm{N}_{2}$ adsorption-desorption isotherm by using the BarrettJoyner-Halenda calculation model.

sons of the physical properties of the acid-made mesoporous silicas using different acid sources, we carefully adjusted the aging time to have similar silica condensation in all of the samples and avoid the formation of side products formation (i.e. amorphous silicas). Fig. 5 reveals the representative X-ray diffraction patterns (XRD) and $\mathrm{N}_{2}$ adsorption-desorption isotherms of the calcined mesoporous materials synthesized from $\mathrm{C}_{16}$ TMAB-TEOS-HX- $\mathrm{H}_{2} \mathrm{O}$ at $30{ }^{\circ} \mathrm{C}$ by using different acid sources $\left(\mathrm{HX}=\mathrm{HCl}, \mathrm{HBr}, \mathrm{HNO}_{3}, \mathrm{H}_{2} \mathrm{SO}_{4}\right)$. One can clearly find that all of these samples possess the 2 to 3 XRD peaks characteristic of hexagonal structure (Fig. 5A). The XRD patterns are almost flat between $2 \theta=20$ and 30 degrees, indicating that no amorphous silica particles were formed. ${ }^{18}$ Moreover, the $\mathrm{N}_{2}$ adsorption-desorption isotherms of the calcined samples have little difference in their patterns and shape (Fig. 5B). Basically, all acid-synthesized samples possess narrow pore size distributions. This result reveals that all of these inorganic acids are suitable for preparing high-quality mesoporous materials under acid condition. The nature of the acid source does not have apparent effects on the nano-structure order of the mesoporous materials. In brief, with a careful control on aging time, the mesoporous materials with well-ordered hexagonal structure can be readily synthesized from various inorganic acids. ${ }^{25}$

\section{Pore Size Control}

We have fabricated the mesoporous materials with different $\mathrm{C}_{\mathrm{n}}$ TMAX ( $\mathrm{n} \geq 14 ; \mathrm{X}=\mathrm{Cl}$ or $\mathrm{Br}$ ) surfactants. The physical properties (including the $\mathrm{d}_{100}$ of the as-synthesized and calcined samples, pore size and BET surface area) of these materials from different acid sources and chain-length surfactants are listed in Table 1. Basically, all these calcined mesoporous materials exhibit large surface area $\left(\sim 1000 \mathrm{~m}^{2} / \mathrm{g}\right)$ and uniform pore size. The products prepared from various surfactant sources with the same carbon chain length but by using different acid sources, have almost the same pore size. It is supposed that the size of the mediated counterion $\mathrm{X}^{-}$is relatively less important in determining the pore size than the chain length of the surfactant. Overall, the d-spacing and pore size is tunable, which increases with the increase of the chain length of the surfactant. ${ }^{34}$ These results are in parallel to those of MCM-41 silicas synthesized from basic media $(\mathrm{pH}>8){ }^{35,36}$

Comparing the shrinkage of the $\mathrm{d}_{100}$ value after calcination at $560{ }^{\circ} \mathrm{C}$, one can find that the shrinkage percentage of the acid-synthesized mesoporous materials is about $10-15 \%$ which is larger than that of basic-made MCM-41 materials (about 5\%). The larger lattice shrinkage indicates that the mesostructures of the acid-made mesoporous silicas are less condensed. Reducing the lattice shrinkage percentage is possible by fine controlling the silica condensation degree at suitable composites and aging time. The mesoporous silicas with high silica condensation can have larger thermal and hy-

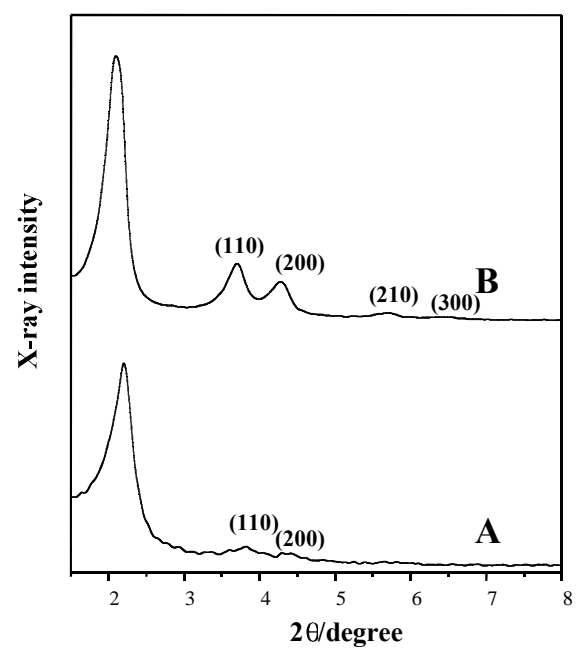

Fig. 6. XRD patterns of the calcined mesoporous samples synthesized from $\mathrm{C}_{16}$ TMAB-HCl-TEOS$\mathrm{H}_{2} \mathrm{O}$ compositions with and without ammonia solution addition. A. without ammonia addition; B. with ammonia addition. 
drothermal stability.

\section{Addition of Ammonia Solution}

To investigate the effect of $\mathrm{NH}_{4} \mathrm{OH}$ addition on the hexagonal structure orderness of the mesoporous materials, the acid-made gel solution after $1 \mathrm{hr}$ aging time was neutralized by adding $\mathrm{NH}_{4} \mathrm{OH}$ aqueous solution to adjust the $\mathrm{pH}$ value to about 8.0 - 9.0, and then further aged for 2 hr. Fig. 6 shows the comparison of the XRD patterns of calcined products prepared with and without $\mathrm{pH}$ value adjustment. It was found that there are extra characteristic peaks of (210) and (300) in ammonia-added samples. The existence of higher diffraction peaks indicates higher orderness. The improvement of mesostructural order of the mesoporous materials can be ascribed to that the $\mathrm{NH}_{4} \mathrm{OH}$ addition transforms the interactions of the silica wall and surfactant from weak hydrogen bonding to strong electrostatic interaction as follows:

$$
\begin{aligned}
& \mathrm{S}^{+} \mathrm{X}^{-} \cdots \mathrm{I}^{0}+\mathrm{NH}_{4} \mathrm{OH} \rightarrow \mathrm{S}^{+} \cdots \mathrm{I}^{-}+\mathrm{NH}_{4} \mathrm{X}+\mathrm{H}_{2} \mathrm{O} \\
& \uparrow \quad \uparrow
\end{aligned}
$$

Weak hydrogen bonding Strong electrostatic interaction

The stronger electrostatic interactions induce the silica wall and surfactant to rearrange and restructure into a well-ordered mesostructure like that prepared from basic route at ambient temperature. ${ }^{37}$

Using the SEM and optical microscope to examine the morphologies of the ammonia-neutralized mesoporous silicas, we found that the morphologies are the same as the original acid-synthesized ones. Thus, this ammonia neutralization process can provide a convenient way to prepare the hierarchical structures under acidic condition with well-ordered mesostructure at ambient temperature, while the alkaline treatment later converts it into alkaline form. ${ }^{34}$

\section{CONCLUSIONS}

Mesoporous materials with hexagonal structure have been synthesized from various acid sources. The behavior of the mesoporous materials formation in acid condition is really relative to that of an acidity-controlled silica-condensation reaction. Thus, we have presented a new procedure to have a fine ability to synthetically control the size and shape of the mesoporous materials according to the silica chemistry and nucleation theory. ${ }^{38-40}$ Many worthwhile results on the synthesis of mesoporous silicas have been laid out; one could stand on these bases and extend important applications in catalysis, separation technology and opticoelectronics.

\section{ACKNOWLEDGMENT}

We thank Mr. Chung-Yuan Tang and Ching-Yuan Lin for helping with the SEM and TEM micrographs preparation. This research was supported by the China Petroleum Co. and the National Science Council of Taiwan (NSC 88-2113-M002-027).

Received July 1, 2002.

\section{Key Words}

Mesoporous; Surfactant; Acid condition; MCM-41.

\section{REFERENCES}

1. Yanagisawa, T.; Shimzu, T.; Kuroda, K.; Kato, C. Bull. Chem. Soc., Jpn. 1990, 63, 988.

2. Zhao, D.; Yang, P.; Hou, Q.; Chmelka, B. F.; Stucky, G. D. Current Opinion in Solid State and Materials Science 1998, $3,111$.

3. Kresge, C. T.; Leonowicz, M. E.; Roth, W. J.; Vartuli, J. C.; Beck, J. S. Nature 1992, 359, 710.

4. Beck, J. S.; Vartuli, J. C.; Roth, W. J.; Leonowicz, M. E.; Kresge, C. T.; Schmitt, K. D.; Chu, C. T.-W.; Olson, D. H.; Sheppard, E. W.; Higgins, S. B.; Schlenker, J. L. J. Am. Chem. Soc. 1992, 114, 10834.

5. Corma, A. Chem. Rev. 1997, 97, 2373.

6. Lee, T., Yao, N.; Aksay, I. A. Langmuir 1997, 13, 3866.

7. Aksay, I. A.; Trau, M.; Manne, S.; Honma, I.; Yao, N.; Zhou, L.; Fenter, P.; Eisenberger, P. M.; Gruner, S. M. Science 1996, 273, 892.

8. Trau, M.; Yao, N.; Kim, E.; Xia, Y.; Whitesides, G. M.; Aksay, I. A. Nature 1997, 390674.

9. Antonelli, D. M.; Ying, J. Y. Curr. Opin. Colloid Interface Sci. 1996, 1, 523.

10. Sayari, A. Chem. Mater. 1996, 8, 1840.

11. (a). Wu, C. G.; Bein, T. Science 1994, 264, 1757. (b). Wu, C. G.; Bein, T. Science 1994, 266, 1013.

12. Monnier, A.; Schüth, F.; Huo, Q.; Kumar, D.; Margolese, D.; R. Maxwell, S.; Stucky, G. Krishnamurty, D.; M.; Petroff, P.; Firouzi, A.; Janicke, M.; Chmelka, B. F. Science 1993, 261, 1299.

13. Firouzi, A.; Kumar, D.; Besier, T.; Sieger, P.; Hou, Q.; Walker, S. A.; Zasadzinski, J. A.; Glinla, C.; Nicol, J.; Margolese, D.; Stucky, G. D.; Chemalka, B. F. Science 1995, $267,1138$.

14. Huo, Q.; Margolese, D. I.; Ciesla, U.; Feng, P.; Gier, T. E.; Sieger, P.; Leon, R.; Petroff,. P. M.; Schüth F.; Stucky, G. D. Nature 1994, 368, 317. 
15. (a). Mann, S.; Ozin, G. A. Nature 1996, 382, 313. (b). Davis, S. A.; Burkett, S. L.; Mendelson, N. H.; Mann, S. Nature 1997, 385, 420.

16. Zhao, D.; Feng, J.; Huo, Q.; Melosh, N.; Fredrickson, G. H.; Chmelka, B. F.; Stucky, G. D. Science 1998, 279, 548.

17. (a). Ozin, G. A.; Yang, H.; Sokolov I.; Coombs, N. $A d v$. $M a-$ ter. 1997, 9, 662. (b). Yang, H.; Coombs, N.; Ozin, G. A. Nature 1997, 386, 692.

18. Lin, H. P.; Liu, S.B.; Mou, C. Y.; Tang, T. Y. Chem. Comm. 1999, 583

19. Schacht, S.; Hou, Q.; Voigt-Martin, I. G.; Stucky, G. D.; Schüth, F. Science 1996, 273768.

20. Ogawa, M.; Igarashi, T.; Kuroda, K. Chem. Mater. 1999, 10, 1382.

21. Imhof, A.; Pine, D. J. Nature 1997, 389, 948.

22. Ryoo, R.; Ko, C. H.; Cho, S. J.; Kim, J. M. J. Phys. Chem. B 1997, 101, 10610 .

23. Voegtlin, A.C.; Ruch, F.; Guth, J. L.; Patarin J.; Huve, L. Microporous Mater. 1997, 995.

24. Tanev, P. T.; Pinnavaia, T. J. Science 1996, 271, 1267.

25. Lin, H. P.; Kao, C. P.; Mou, C. Y.; Liu, S. B. J. Phys. Chem. B 2000, 104, 7885 .

26. (a). Dorshow, J. van; Biggs, R. B.; Bunton, C. A.; Nicoll, D. F. J. Phys. Chem. 1983, 87 1409.; (b). Gamboa, C.; Ríos, H.; Sepúlveda, L. J. Phys. Chem. 1989, 93, 5504.

27. Fendler, J. H.; Fendler, E. J. Catalysis in Micellar and Macromolecular Systems; Academic Press: New York, 1975.

28. (a). Iler.; R. K. The Chemistry of Silica; John-Wiley: New York, 1979. (b). Brinker, C. J.; Scherer, G. W. J. NonCrystal. Sol. 1985, 70, 301.

29. Zhao, D.; Huo, Q.; Feng, J.; Chmelka, B. F.; Stucky, G. D. J. Am. Chem. Soc. 1998, 120, 6024.
30. Yang, S. M.; Yang, H.; Coombs, N.; Sokolov, I.; Kresge, C. T.; Ozin, G. A. Adv. Mater. 1999, 11, 52.

31. Fowler, C. E.; Khushalani, D. Lebeau, B.; Mann, S. Adv. Mater. 2001, 13, 649.

32. Yang, H.; Kuperman, A.; Coombs, N.; Mamiche-Afara, S.; Ozin, G. A. Nature 1996, 379, 703.

33. D. F. Evans, H. Wennerström The Colloidal Domain; VHC: New York, 1994.

34. (a). Lin, H. P.; Mou, C. Y. Science 1996, 273, 765. (b). Cheng, Y. R.; Lin, H. P.; Mou, C. Y.; Liu, S. B. Chem. Phys. Phys. Chem. 1999, 21, 5138.

35. (a). Lin, H. P.; Kao, G. P.; Mou, C. Y. Microporous and Mesoporous Mater. 2001, 48, 135. (b). Lin, H. P.; Cheng, S.; Mou, C. Y. Microporous Material 1997, 10, 111-121.

36. (a) Huo, Q.; Margolese, D. I.; Ciesla, U.; Demuth, D. G.; Feng, P.; Gier, T. E.; Sieger, P.; Firouzi, A.; Chmelka, B. F.; Schüth F.; Stucky, G. D. Chem. Mater. 1994, 6, 1176. (b) Hou, Q.; Margolese, D. I.; Stucky, G. D. Chem. Mater. 1996, 8,1147 .

37. (a). Lin, H. P.; Mou, C. Y.; Liu, S. B. Chem. Lett. 1999, 1341. (b). Lin, H. P.; Mou, C. Y.; Liu, S. B.; Tang, C. Y.; Lin, C. Y. Microporous and Mesoporous Mater. 2001, 44-45, 129.

38. Schacht, S.; Hou, Q.; Voigt-Martin, I. G.; Stucky, G. D.; Schüth, F. Science 1996, 273, 768.

39. (a) Brown, A. S.; Holt, S. A.; Reynolds, P. A.; Penfold, J.; White, J. W. Langmuir 1998, 14, 5532.; (b). Lindén, M.; Schacht, S.; Schüth, F.; Steel, A.; Unger, K. K. J. Porous Mater. 1998, 5, 177.; (c). Hillhouse, H. W.; Okubo, T.; Egmond, J. W. V.; Tsapatsis, M. Chem. Mater. 1997, 9, 1505.

40. C. Tanford The Hydrophobic Effect: Formation of Micelles and Biological Membranes; Wiley: New York, 1973. 